\title{
Numerical study on heat transfer in laminar flow through co-rotating parallel disks
}

\author{
YOON S. SIM and WEN-JEI YANG \\ Department of Mechanical Engineering and Applied Mechanics, \\ University of Michigan, Ann Arbor, MI 48109, U.S.A.
}

(Received 27 May 1983 and in revised form 6 December 1983)

\begin{abstract}
A theoretical model is developed to determine heat transfer performance in laminar flow through a pair of co-rotating parallel circular disks. The dual-stream flow influx enters the flow field from both sides, proceeding radially outward. A finite-difference scheme is employed to obtain numerical results by means of the SIMPLER algorithm. The effects of governing dimensionless parameters such as the rotational number through-flow Reynolds number, Prandtl number and system geometry on the heat transfer performance are determined.
\end{abstract}

\section{INTRODUCTION}

RoTATING mechanical devices associated with heat and mass transfer are abundant in industry, for example, turbomachinery [1], rotating heat exchangers $[2,3]$ and rotating-disk contactors [4]. Rotating-disk systems have bcen employed as the modcls for the flow and heat/mass transfer that occur inside these units. They can be classified into the free disk, rotor-stator systems and rotating cavities [1]. Among them, the free disk is the simplest model which has received considerable attention. It is the basis of all rotorstator systems and also has relevance to rotating cavities. Both the rotor-stator system and the rotating cavity have been the subject of numerous experimental and theoretical studies. Instead of repeating a review of voluminous articles on rotating-disk systems, readers are referred to Dorfman [5] concerning rotor-stator systems; Greenspan [6] which includes a large quantity of material on rotating cavities; and a recent article by Owen [1] reviewing fluid flow and heat transfer in rotating-disk systems.

Although there are many publications devoted to rotating-disk systems, a number of important areas still need further theoretical and experimental research. The prcsent work explores such areas. It deals with heat transfer in laminar flow through a pair of co-rotating parallel circular disks. A theoretical model is developed. Numerical results are obtained by the SIMPLER algorithm [7].

\section{ANALYSIS}

Figure 1 shows the physical system to be analyzed. It consists of two parallel circular disks with an opening of diameter $2 r_{\text {in }}$ at the center. A fluid flows normally through the openings and then radially out through the spacing $B$ between the disks of outer radius $r_{\mathrm{o}}$. A cylindrical coordinate $(r, z)$ is used with the origin fixed at the center of the lower disks. It is postulated that the flow is steady, laminar, incompressible and axi- symmetrical and that all physical properties remain constant.

The differential equations governing transport phenomena in a radial channel between parallel disks give this continuity equation

$$
\frac{1}{r} \frac{\partial}{\partial r}(r u)+\frac{\partial v}{\partial z}=0
$$

and transfer equations in a unified form

$$
\frac{1}{r} \frac{\partial}{\partial r}(r u \phi)+\frac{\partial}{\partial z}(v \phi)=\frac{1}{r} \frac{\partial}{\partial r}\left(r c \frac{\partial \phi}{\partial r}\right)+\frac{\partial}{\partial z}\left(c \frac{\partial \phi}{\partial z}\right)+S_{\phi}
$$

In Table $1, p$ is the pressure and $v$ and $\alpha$ are the kinematic viscosity and thermal diffusivity, respectively. It is assumed that (1) both the velocity and temperature profiles are uniform at the inlet to the radial channel $\left(r=r_{\text {in }}\right.$ at $u_{\text {in }}$ and $T_{\text {in }}$, respectively) and (2) the channel wall temperature is uniform at $T_{w}$. Assumption (1) is reasonable if the rotating-disk assembly is placed in the midstream within a wind tunnel duct. The flow is non-slip at the wall. It can be shown that at the outlet $r=r_{0}$ the radial diffusion effect is negligible compared with the radial convective effect for all the velocity components and temperatures. Two cases are studied : the disks are at rest and in rotation about the $z$-axis while the fluid is flowing radially outward.

The flow field in the lower half channel was divided

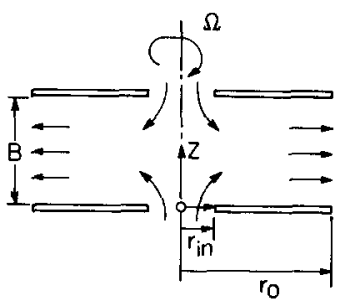

Fig. 1. A side view of two co-rotating parallel circular disks 


\section{NOMENCLATURE}

a coefficient

$b$ gap between the disks [m]

$G x$ generalized flow coordinate, equation (9)

$h$ heat transfer coefficient $\left[\mathrm{W} \mathrm{m}^{-2} \mathrm{~K}^{-1}\right]$

$\bar{h}$ integrated mean heat transfer coefficient [W $\mathrm{m}^{-2} \mathrm{~K}^{-1}$ ]

$i$ grid counter in $r$-direction

I $i$-counter of the nodes immediately before the exit

$j \quad$ grid counter in $z$-direction

$J \quad j$-counter of the nodes immediately below the center plane

$k$ fluid thermal conductivity $\left[\mathrm{W} \mathrm{m} \mathrm{m}^{-1} \mathrm{~K}^{-1}\right.$ ]

$m$ total mass flow rate $\left[\mathrm{kg} \mathrm{s}^{-1}\right]$

$p$ pressure $\left[\mathrm{N} \mathrm{m}^{-2}\right]$

$p^{\prime} \quad$ variable for correcting velocity

$\operatorname{Pr}$ Prandtl number

$q$ total heat transfer rate [W]

$Q$ non-dimensionalized $q$, equation (7)

$N u$ Nusselt number, equation (7)

$\overline{N u}$ integrated mean Nusselt number

$R$ disk radius divided by $(B / 2): R_{\mathrm{in}}$ at inlet; $R_{\mathrm{o}}$ at exit

$r$ radial coordinate $: r_{\text {in }}$, inner disk radius; $r_{\mathbf{o}}$, outer disk radius [m]

$\operatorname{Re}$ Reynolds number, equation (8)

$R t$ rotation number, equation (9)

$T$ temperature: $T_{\text {in }}$, temperature of inlet fluid; $T_{\mathrm{w}}$, temperature of disk wall $\left[{ }^{\circ} \mathrm{C}\right]$
Ta Taylor number, equation (9)

$u$ radial velocity component: $u_{\text {in }}$ at inlet $\left[\mathrm{m} \mathrm{s}^{-1}\right]$

$v \quad$ axial velocity component $\left[\mathrm{m} \mathrm{s}^{-1}\right]$

$w$ angular velocity component $\left[\mathrm{m} \mathrm{s}^{-1}\right]$

$z$ axial coordinate [m].

\section{Greek symbols}

$\alpha \quad$ thermal diffusivity $\left[\mathrm{m}^{2} \mathrm{~s}^{-1}\right]$

0 angular coordinate

$\mu \quad$ viscosity [ $\mathrm{N} \mathrm{s} \mathrm{m}^{-2}$ ]

$v \quad$ kinematic viscosity $\left[\mathrm{m}^{2} \mathrm{~s}^{-1}\right]$

$\phi \quad$ variables (general)

$\Omega \quad$ angular vclocity of rotating disks $\left[\mathrm{m} \mathrm{s}^{-1}\right]$.

\section{Subscripts}

e east wall of a grid cell

E east node

$i$ radial grid counter

in inlet

$j \quad$ axial grid counter

$\mathrm{n}$ north wall of a grid cell

$\mathrm{N}$ north node

o outlet

P center node

$\mathrm{s}$ south wall of a grid cell

$S$ south node

w wall. into a non-uniform grid network of rectangular shape (with grid size of $\Delta r_{i} \times \Delta z_{j}$ ), $I \times J$ meshes in the radial and axial directions, respectively, as shown in Fig. 2. The governing equations (1) and (2) were reduced to a set of algebraic finite-difference equations using a discretization method called the hybrid scheme [7-9] which is a combination of the central and upwind schemes.

In the present study, the discretized governing equations were solved by the SIMPLER (semi-implicit pressure-linked equations revised) algorithm [7]:

Table 1. Definition of $c$ and $S$

\begin{tabular}{ccc}
\hline \multicolumn{1}{c}{$c$} & $c$ & \multicolumn{1}{c}{$s$} \\
\hline$v$ & $v$ & $-\frac{\partial p}{\partial r}-v \frac{u}{r^{2}}+\frac{w^{2}}{r}$ \\
$w$ & $v$ & $-\frac{\partial p}{\partial z}$ \\
$T$ & $v$ & $-\frac{w}{r^{2}}-\frac{u w}{r}$ \\
\hline
\end{tabular}

pressure was determined from the equation derived by coupling of the discretized momentum equations to the discretized continuity equations, while the velocity determined by the momentum equation was corrected to satisfy the continuity equation through the use of an additional variable $p^{\prime}$. The equations for $p^{\prime}$ were derived also by coupling of the discretized momentum equations to the discretized continuity equation. However, the difference equations for each dependent variable were solved by the line-by-line interactive method.

New schemes were incorporated in the present study in order to increase the accuracy of the numerical scheme and to reduce the number of steps required for convergence and also to improve the numerical stability in computations.

\subsection{New treatment of the velocity correction through $p^{\prime}$ at the exit}

In the conventional treatment $[9,10]$, the boundary condition for $p^{\prime}$ at the exit is provided by assigning 0 to the $a_{\mathrm{E}}$ coefficients which relate $p^{\prime}$ s at $i=I$ and at $i=$ $I+1$. It makes the system of the difference equations for $p^{\prime}$ a singular system, which has generally a faster convergence rate in the difference among $p^{\prime}$ 's than a non- 


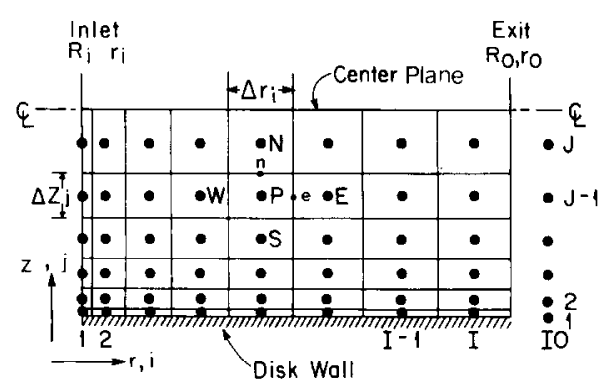

Fig. 2. Flow field and numerical grid.

singular system. This scheme, however, can satisfy only the overall continuity at the outlet but not the continuity at each cell. Thus, it may result in large continuity errors in this region even in a final solution which has already passed a convergency test. To remedy this defect, a new treatment was devised which was based on the fact that the difference between $p$ 's in the $z$-direction is much smaller than that in the $r$ direction, which will be explained in more detail in Section 2.2. From this consideration, a constant 0 was assigned to all $p$ 's at $i=I+1$. Since the linkage between $p^{\prime}$ s at $i=I$ and $i=I+1$ are not served, the continuity at each exit cell can be satisfied through the non-uniform correction of the exit velocity and the error in the continuity in the exit region can be thus reduced to the level of other regions.

\subsection{Initial guessing of the additional variable $p^{\prime}$ for an inner iteration}

Even though accuracy is improved, the new treatment at the exit in Section 2.1 changes the system to a non-singular one, whose convergence rate becomes slower. This is very important since the value of $p^{\prime}$ changes at each global iteration and only a few inner iterations can be performed for $p^{\prime}$ at each global iteration. A good initial guess of $p^{\prime}$, however, can be found by calculating the average value of $p^{\prime}$. The velocity-correction formulas (7) at nodal point $P$ are

$$
\begin{aligned}
& u_{\mathrm{e}}=u_{\mathrm{e}}^{*}+d_{u}\left(p_{\mathrm{P}}^{\prime}-p_{\mathrm{E}}^{\prime}\right) \\
& v_{\mathrm{n}}=v_{\mathrm{n}}^{*}+d_{v}\left(p_{\mathrm{P}}^{\prime}-p_{\mathrm{N}}^{\prime}\right) .
\end{aligned}
$$

A similar expression is obtained for $u_{\mathrm{w}}$ and $u_{\mathrm{s}} \cdot u^{*}$ and $v^{*}$ are the velocities determined by the momentum equations. They are corrected by $p^{\prime}$ to satisfy the continuity. Values of $d$ are proportionality coefficients. Since $\left(u_{\mathrm{e}}-u_{\mathrm{e}}^{*}\right)$ is generally much larger than $\left(v_{\mathrm{n}}-v_{\mathrm{n}}^{*}\right)$ while the proportionality coefficients $d_{u}$ and $d_{v}$ are almost the same, the difference between $p_{\mathrm{P}}^{\prime}$ and $p_{\mathrm{E}}^{\prime}$ becomes much larger than that between $p_{\mathrm{P}}^{\prime}$ and $p_{\mathrm{N}}^{\prime}$. Consequently, $p^{\prime}$ undergoes a major change only in the $r$-direction. This feature makes it possible to determine the average $p^{\prime}$ at each $i$ which can be used as a good initial guess. Only a fine adjustment of $p^{\prime}$ across the channel ( $j$-direction) is required for inner iteration. The average value is calculated by adding the difference equation (7) for $p^{\prime}$ over the $j$-direction. The result is

$$
\left(\sum_{j} a_{\mathbf{P}_{i j}}\right) \bar{p}_{i}^{\prime}=\left(\sum_{j} a_{\mathbf{E}_{i j}}\right) \bar{p}_{i+1}^{\prime}+\left(\sum_{j} a_{\mathbf{w}_{i j}}\right) \bar{p}_{i-1}^{\prime}+\sum_{j} b_{i j}
$$

Here, values of $a$ are the coefficients which define the relationship between $p^{\prime}$ at the center node $\mathbf{P}$ and the surrounding nodes at $\mathrm{E}$ and $\mathrm{W}$, while the term $b_{i j}$ represents a 'mass source' which must be annihilated through the velocity correction. A more detailed explanation can be found in ref. [11].

\subsection{Initial guessing of pressure $p$}

Since the equations for $p$ and $p^{\prime}$ are similar in characteristics, a good initial guess of $p$ can be conducted in a similar fashion as that for $p^{\prime}$ as described in Section 2.2. When the following condition was satisfied, $p_{i, j}^{(-1)}$ was employed as a starting value for an inner iteration

$$
\sum_{j=2}^{J}\left|\bar{p}_{i}-p_{i, j}\right| \geqq \sum_{j=2}^{J}\left|p_{i, j}^{(-1)}-p_{i, j}\right|
$$

where $p_{i, j}^{(-1)}$ is the value of $p_{i, j}$ at the previous iteration. This criterion was usually achieved in seven to ten iterations.

\subsection{Modification of the coefficient of $p^{\prime}$ in the central region of the flow field}

$a_{\mathrm{p}}$, a coefficient of $p^{\prime}$ in the difference equation of $p^{\prime}$, is a function of similar coefficients in the discretized momentum equations while the coefficients in the momentum equations depend on the boundary conditions for velocity. With this functional relationship, the symmetry condition on the center plane for $u$ makes the coefficient $a_{\mathrm{p}}$ at nodal points $(i, J)$ significantly different from the $a_{\mathrm{p}}$ at other nodal points at the same radial location. It results in an overcorrection of $u$ at the nodal points $(i, J)$. The overcorrection deteriorates the satisfaction of the momentum equations even though it satisfies the continuity equation. The satisfaction of the momentum equations can be improved by adjusting the proportionality coefficient, values of $d$ in equations (3) and (4), without affecting the satisfaction of the continuity equation. To prevent the over-correction due to the symmetry condition, modification was made on the coefficient $a_{\mathrm{p}}^{u}$, which is a coefficient for $u_{\mathrm{p}}$ in the discretized momentum equation. When the proportionality coefficients of $d$ are calculated from the $a_{\mathrm{p}}^{u}$, the $a_{\mathrm{p}}^{u}$ at $(i, J)$ was set equal to the $a_{\mathrm{P}}$ at $(i, J-1)$. The modification was crucial in achieving the convergence, especially when the $\Delta r / \Delta z$ ratio of a grid cell was largc.

\subsection{Use of different relaxation factors for global and inner iterations}

The under-relaxation factors of $0.7,0.7,0.7$, and 0.5 were used for the calculations of $u, v, w$, and $p$, respectively, in the global iterative procedure, while 1.0 and 0.7 and 1.0 were utilized as the relaxation factors of 
Table 2. Methods and required CPU time for channel flow between two parallel plates of channel length - height ratio of $20, R e=200$ and $30 \times 15$ grid system

\begin{tabular}{ccc} 
Method & $\begin{array}{c}\text { Guessing of } p^{\prime} \text { and } P \\
\text { in inner iteration }\end{array}$ & $\begin{array}{c}\text { CPU } \\
\text { time } \\
\text { (s) }\end{array}$ \\
\hline $\begin{array}{l}\text { New method } \\
\left(p^{\prime}=0 \text { at } i=I+1\right)\end{array}$ & Yes & 2.43 \\
$\begin{array}{c}\text { Conventional method } \\
\left(\text { for } p^{\prime}, a_{\mathrm{E}}=0 \text { at } i=I\right)\end{array}$ & No & 3.58 \\
\hline
\end{tabular}

$u, v$, and $w$, respectively, for their inner iterations. An over-relaxation factor between 1.5 and 1.7 was employed for the inner iterations of $p$ and $p^{\prime}$.

Table 2 shows the effectiveness of the new measure introduced in this study.

The solution of the discretization equations was obtained by the TDMA (tridiagonal-matrix algorithm) [12]. Computations progressed in the radial direction from the boundary where an explicit condition was specified toward the opposite side.

The convergence criteria were set as

$$
\frac{\sum_{i=1}^{I} \sum_{j=1}^{J}\left|b_{i, j}\right|}{\sqrt{\left[\left(R_{\mathrm{o}}^{2}-R_{\mathrm{in}}^{2}\right) I J\right]}}<0.0002 \text { and }\left|u_{\mathrm{c}}-u_{\mathrm{e}}^{*}\right|_{\max }<0.004 \text {. }
$$

Here, $b_{i, j}$ denotes the error in the continuity equation at the cell centered at the nodal point $(i, j) . u_{\mathrm{e}}$ and $u_{\mathrm{e}}^{*}$ are the values of $u$ at the point $(i, j)$ determined by the velocitycorrection formula and the discretized momentum equations, respectively, in the SIMPLER algorithm.

\section{RESULTS AND DISCUSSION}

Numerical computations were performed using an AMDAHL 5860 digital computer with an II compiler. The accuracy of the mathematical model and computer program was first tested by solving the problem of a fully developed channel flow using a rectangular grid network. The largest error in the velocity components was found in the $u$ value to be $0.6 \%$, whereas the error in the pressure gradient was $0.3 \%$ with a network of 20 $\times 15$ meshes when $R e=200$. Numerical computations were also performed to determine local heat transfer coefficients in slug flow througl a radial channel between stationary parallel disks at uniform wall temperature. For Reynolds numbers of 18850 and 94240 , numerical results were in excellent agreement with the exact solution throughout the entire radial flow path except in the thermal entrance region.

Then, the model and computer program were applied to solve the problem of flow and heat transfer in the radial channcl between rotating parallel disks. $I$ and $J$ were selected as 28 and 15 , respectively. Approximately 5-10 s of CPU time were consumed for each computation.

The heat transfer performance of radial flow through the rotating parallel disks can be expressed in terms of the dimensionless heat transfer rate $Q$, local Nusselt number $N u$, and average Nusselt number $\overline{N u}$. They are defined as

$$
Q=\frac{q}{k B\left(T_{\mathrm{in}}-T_{\mathrm{w}}\right)} ; \quad N u=\frac{h B}{k} ; \quad \overline{N u}=\frac{\bar{h} B}{k} .
$$

Here, $q$ denotes the total heat transfer rate between the disk wall and the bulk fluid, $k$ the fluid thermal conductivity, $B$ the disk spacing, $T_{\text {in }}$ the inlet fluid temperature, $T_{\mathrm{w}}$ the disk temperature, $h$ the local heat transfer coefficient, and $\bar{h}$ the integrated average value of $h$. The Reynolds number based on the disk spacing is defined as

$$
R e=\frac{\dot{m}}{B \mu}
$$

where $m$ is the mass flow rate and $\mu$ is the absolute viscosity. In addition to $R e$ and $P r$, the heat transfer performance depends on the Taylor number Ta or the rotational number $R t$ and the system geometry represented by the generalized flow coordinate $G x$.

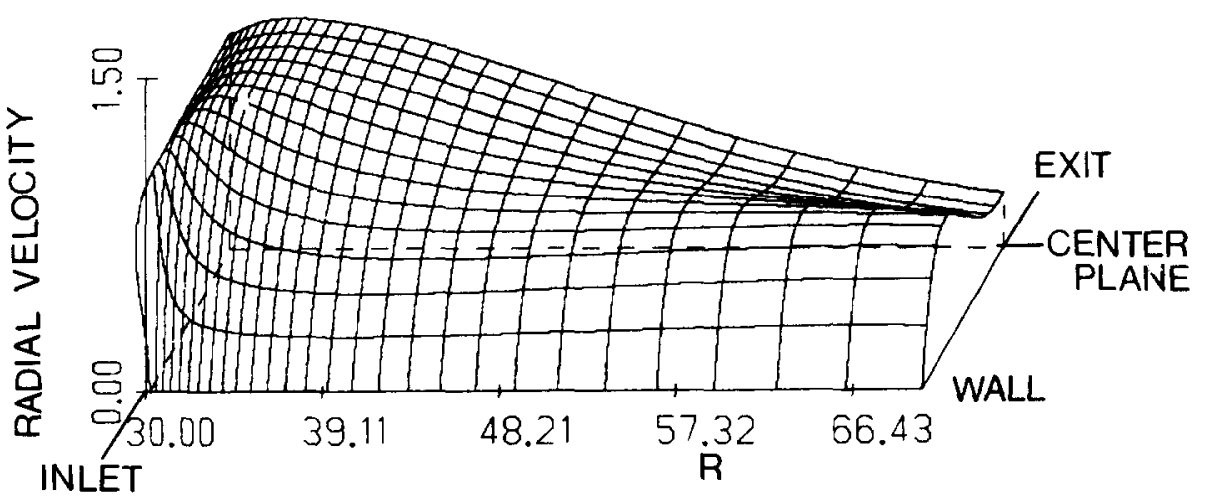

FIG. 3. Distribution of radal velocity component $u$ in a flow with $R e=25200$ through disks $\left(R_{\text {in }}=30\right.$, $R_{\mathrm{o}}=67.5$ ) rotating at $R t=2.0$. 


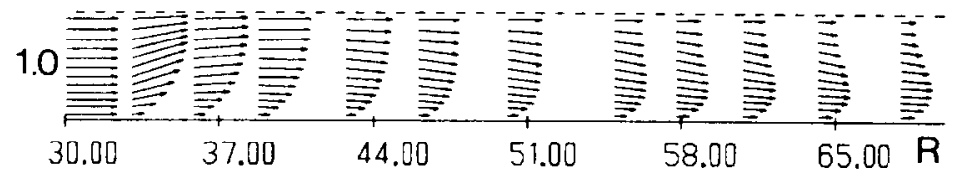

FIG. 4. Distribution of velocity vectors on $r-z$ plane in a flow with $R e=25200$ through disks $\left(R_{\text {in }}=30\right.$, $R_{\mathrm{o}}=67.5$ ) rotating at $R t=2.0$.

They are defined as

$$
T a=\frac{B^{2} \Omega}{v} ; \quad G x=\frac{\pi\left(R^{2}-R_{\mathrm{in}}^{2}\right)}{\operatorname{RePr}} ; \quad R t=\frac{r_{\mathrm{in}} \Omega}{u_{\mathrm{in}}}
$$

where $\Omega$ represents the angular velocity, $u_{\text {in }}$ the radial velocity at the inlet, $R_{\mathrm{in}}=2 r_{\mathrm{in}} / B$, and $R=2 r / B$. Note that $R t R e=2 \pi T a\left(r_{\mathrm{in}} / B\right)^{2}$.

The parametẹrs were varied to determine their effects on the heat transfer performance: $R e=20000$ $140000, \quad P r=0.7-8.0, \quad R t=0-3, \quad R_{\text {in }}=5-80$ and $R_{\mathrm{o}}=40-206$. In the interest of brevity, only typical results are presented here.

It is well recognized that radial flow through parallel disks results in a decrease in the radial velocity due to an enlargement in the flow area. Consequently, a continuous pressurc buildup, i.e. an adverse pressure gradient, along with the flow induces flow separation to occur at a distance downstream from the inlet. When the disks are set in rotation, the centrifugal force comes into play. Its effect is to shift the peak of radial velocity profile $u$ from the channel center (in the entrance region) toward the wall (near the exit), as shown in Fig. 3. As a result, several interesting phenomena are observed. (1) On the $r-z$ plane, the bulk flow as indicated by velocity vectors shifts its direction from center-bound near the entrance to wall-bound, as depicted in Fig. 4. The location of the maximum magnitude of these vectors also shifts from the channel center toward the wall along the radial direction. (2) On the $r-\theta$ plane, the flow vectors are maximum at the wall and increase along the channel but reduce toward the center, as seen in Fig. 5 . The flow direction is tangential at the wall. With an increase in $z$, however, the flow velocity decreases with its direction shifting radially outward. Factors (1) and (2) contribute to heat transfer enhancement by rotating the disk walls, as will be discussed later. (3) Figure 6 shows the pressure distribution which is determined by the combination of viscous effect, momentum change due to an increase in flow area, and centrifugal effect. The viscous effect is most prominent in the region of steep velocity gradients. The momentum change is large at the inlet where the radius is smallest, while the centrifugal effect is most important at the exit where the radius is the largest. It is seen in Fig. 6 that pressure falls to a minimum, followed by a continuous increase.

Figure 7 shows the effects of rotational speed $R t$, radius $R_{\text {in }}$ and generalized flow coordinate $G x$ on the local Nusselt number for $\operatorname{Pr}=0.7$ and $R e=267.5$. $G x$ is defined as $\pi\left(R^{2}-R_{\mathrm{in}}^{2}\right) / P e$, in which $\pi\left(R^{2}-R_{\mathrm{in}}^{2}\right)$ signifies the wetted surface area of a disk from the inlet $R_{\mathrm{in}}$ to a location $R$ in dimensionless form. $P e$ is the Peclet number defined as the product of $R e$ and $P r$. It is

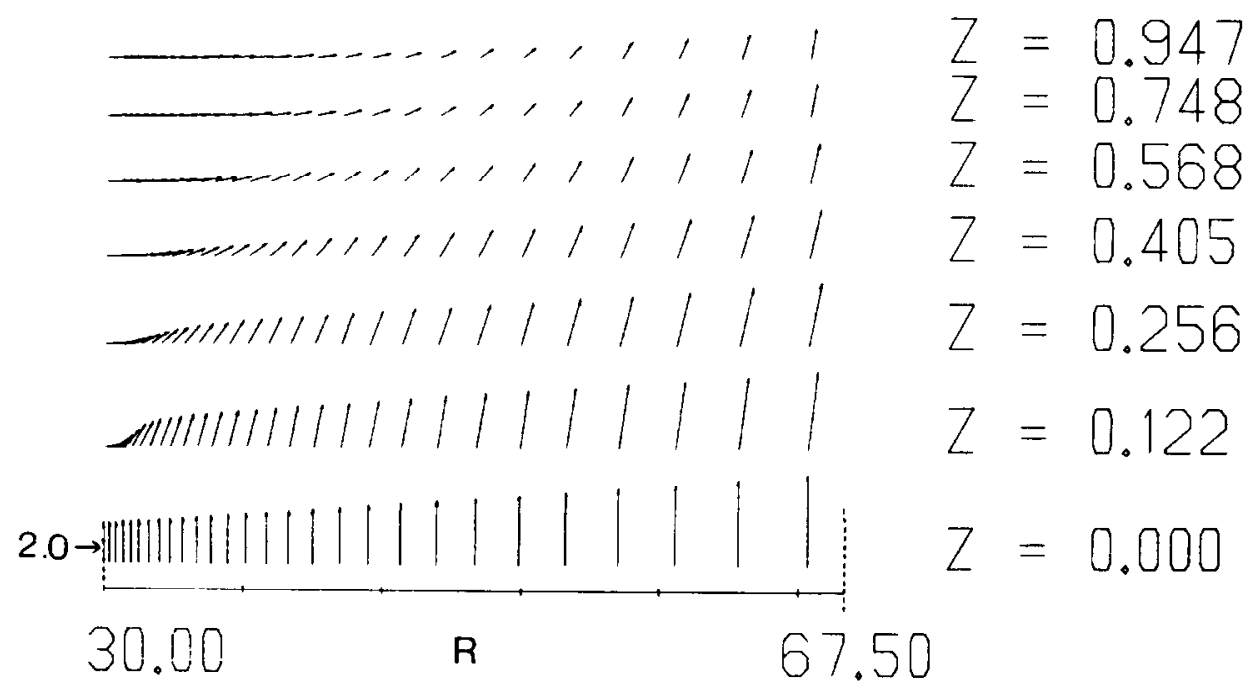

Fig. 5. Distribution of velocity vectors on $r-\theta$ plane in a flow with $R e=25200$ through disks $\left(R_{\mathrm{in}}=30\right.$, $R_{\mathrm{o}}=67.5$ ) rotating at $R t=2.0$. 


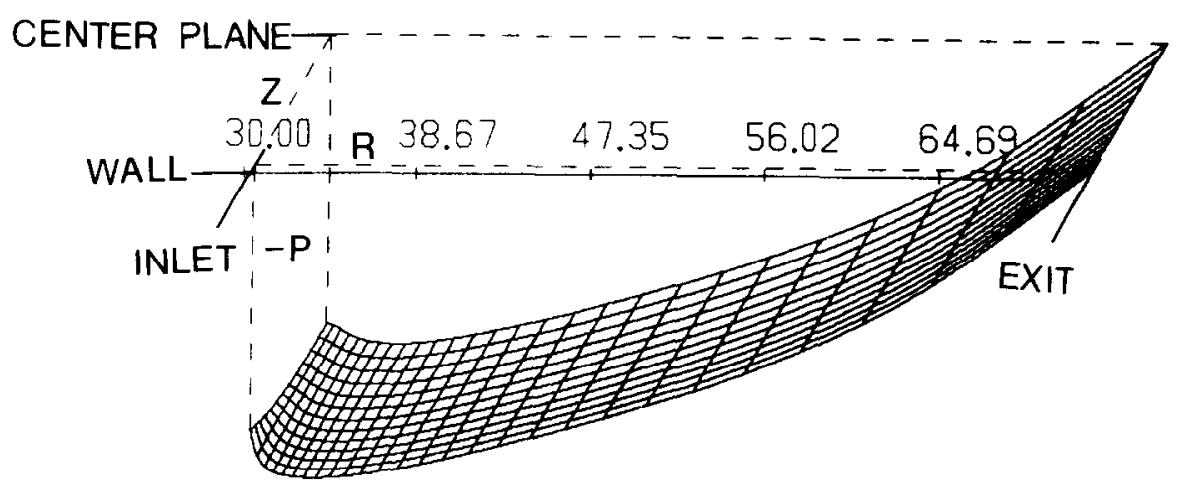

FIG. 6. Pressure distribution in a flow with $R e=25200$ through disks $\left(R_{\mathrm{in}}=30, R_{\mathrm{o}}=67.5\right)$ rotating at $R t=2.0$.

observed in the figure that $N u$ decreases steeply in the entrance region, i.e. small values of $G x$. In the stationary disk case, $N u$ eventually takes a value of 3.7 as $G x$ increases. With disk rotation, the value of $N u$ reaches a minimum followed by an upturn and eventually levels off at large $G x$ values. An increase in $R_{\text {in }}$ reduces the extent of an upturn in $\mathrm{Nu}$.

The effect of Re on $N u$ is shown in Fig. 8 for $P r=0.7$ and a fixed disk geometry, i.e. $R_{\mathrm{in}}=60$ and $R_{0}=130$. As seen in Fig. 7, there is a sharp decrease in $N u$ in the entrance region. $N u$ takes a value of 3.78 at large values of $G x$, irrespective of $R e$ in the stationary disk case. At higher fluid fiows, $N u$ is characterized by a minimum value. When the disks are in rotation, $N u$ reaches a minimum followed by an upturn and then levels off at large $G x$. In general, $N u$ increases with disk rotation $R t$ and fluid flow rate $R e$.

The integrated-averagc Nusselt number $\overline{N u}$ is plotted against the inlet Reynolds number Re in Fig. 9 for two typical fluids, air (with $P r=0.7$ ) and water (at $\operatorname{Pr}=8.0$ ). It is of interest to observe that when all curves are extrapolated toward lower $R e$, they reach $\overline{N u}=3.8$ at $R e=0$, which corresponds to the Nusselt number for a fully-developed laminar flow in parallel channels

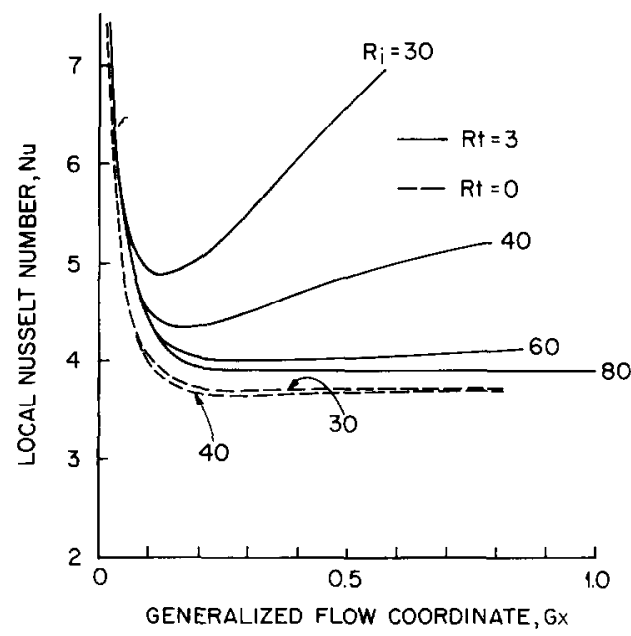

Fig. 7. Effect of $R t$ and $G x$ on $N u$ for $R e=25200$ and $P r=0.7$.

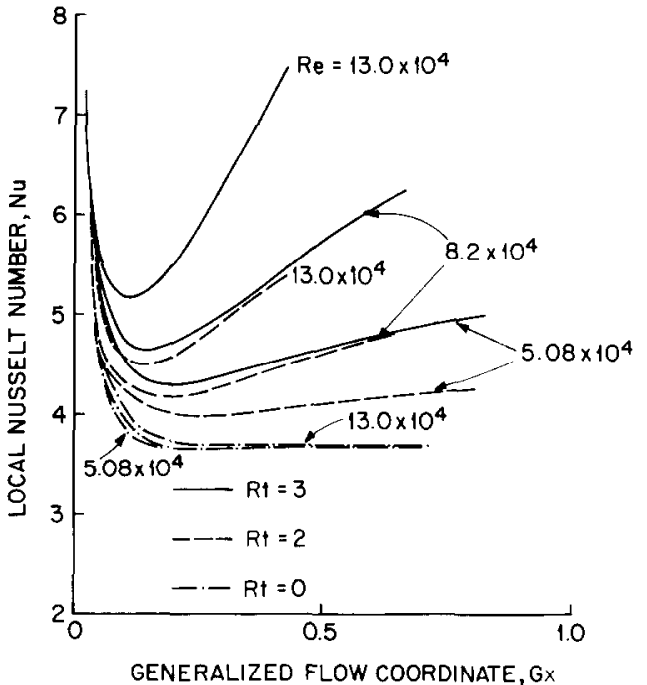

FIG. 8. Effect of $R t$ and $R e$ on $N u$ for $R_{\text {in }}=60, R_{0}=130$ and $P r=0.7$.

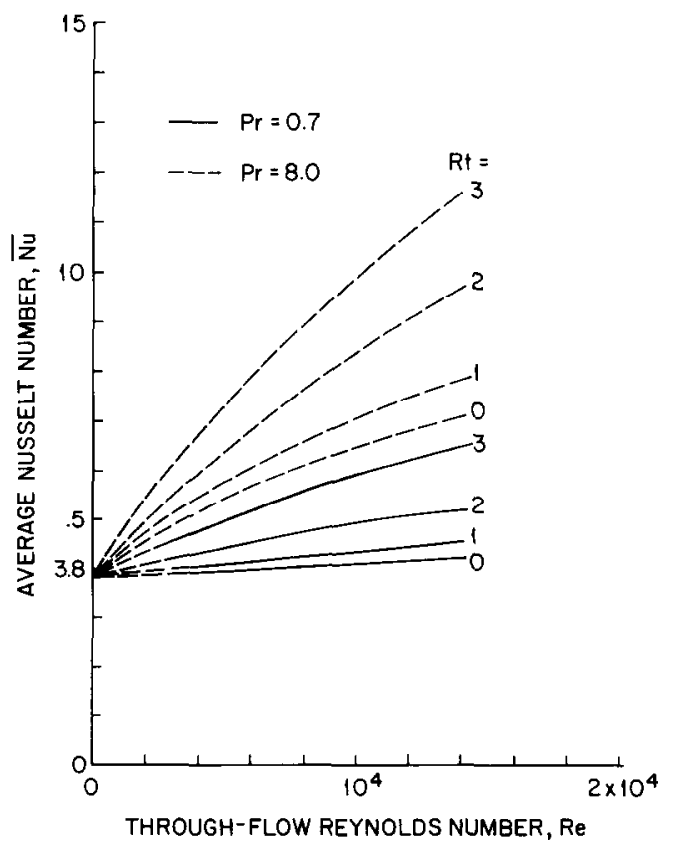

Fig. 9. Eflect of $P r, R e$ and $R t$ on $N u$ for $R_{\mathrm{in}}=60$ and $R_{\mathrm{o}}=130$. 


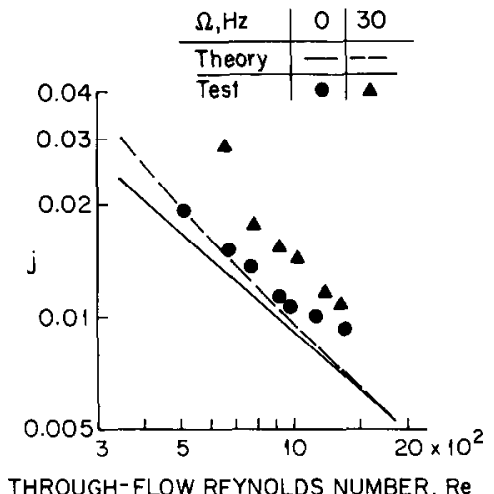

FIG. 10. Comparison of theoretical and test results for $j$.

having constant wall temperature. The reason for all curves in Fig. 9 to converge at $\overline{N u}=3.8$ at $R e=0$ is due to a large diffusion effect. Theory underpredicts the test results as shown in Fig. 10.

\section{CONCLUSION}

A theoretical model is developed to predict the heat transfer performance in flow through parallel circular disks at rest or in rotation. With a dual-stream influx, the flow is radially outward. A finite-difference scheme is employed to obtain numerical results by means of the SIMPLER algorithm. Heat transfer performance is enhanced with rotational speed, Prandtl number and through-flow Reynolds number. It deteriorates with an increase in the inner radius of the parallel circular disks.

Acknowledgement - This research work was supported by the National Science Foundation under Grant No. CME 8018031.

\section{REFERENCES}

1. J. M. Owen, Fluid flow and heat transfer in rotating disc systems, Proceedings of the 1982 International Center for Heat and Mass Transfer Symposium on Heat and Mass Transfer in Rotating Machinery (edited by D. E. Metzger). Hemisphere, Washington, DC (1983).

2. E. W. Eisele, W. Leidenfrost and A. E. Muthunayagam, Studies of heat transfer from rotating heat exchangers, in Progress in Heat and Mass Transfer (edited by T.F. Irvine, W. E. Ibele, J. P. Hartnett and R. J. Goldstein), Vol. 2, pp. 483-498. Pergamon Press, Oxford (1969).

3. S. Mochizuki and W. J. Yang, Heat transfer and friction loss in laminar radial flows through rotating annular disks, Trans. Am. Soc. Mech. Engrs, Series C, J. Heat Transfer 103, 212-217 (1981).

4. W. J. Yang, Gas-liquid mass transfer in rotating performance disc contractors, Lett. Heat Mass Transfer 9 , 119-129 (1982)

5. L. A. Dorfman, Hydrodynamic Resistance and Heat Loss of Rotating Solid. Oliver \& Boyd, Edinburgh (1963).

6. H. P. Greenspan, The Theory of Rotating Fluid, Cambridge University Press, Cambridge (1968).

7. S. V. Patankar, Numerical Heat Transfer and Fluid Flow (1st edn.), pp. 88, 123-125. Hemisphere, Washington, DC (1980).

8. D. B. Spalding, A novel finite difference formulation for differential expressions involving both first and second derivatives, Int. J. Numerical Methods 4, 551-559(1972).

9. A. D. Gosman and W. U. Pun, Calculations of recirculating flows, Lecture Notes, HTS/74/2, Department of Mechanical Engineering, Imperial College, London (1973).

10. D. G. Lilley and D. L. Rhode, A computer code for swirling turbulent axisymmetric recirculating flows in practical isothermal combustion geometries, NASA Contractor Report 3443 (1982).

11. Y.S. Sim, A numerical and experimental study on the flow and heat transfer characteristics in co-rotating disk systems, Ph.D. thesis, University of Michigan, Ann Arbor, Michigan (1983)

12. B. Carnahan, H. A. Luther and J. O. Wilkes, Applied Numerical Methods (1st edn.), p. 441. Wiley, New York (1969).

\section{ETUDE NUMERIQUE DU TRANSFERT DE CHALEUR EN ECOULEMENT LAMINAIRE ENTRE DISQUES PARALLELES CO-ROTATIFS-}

Résumé --On développe un modèle théorique pour déterminer le transfert thermique en écoulement laminaire entre une paire de disques circulaires, parallèles et co-rotatifs. Le double flux d'entrée se fait par les deux côtés et la sortie se fait radialement. Un schéma de différences finies est employé pour obtenir des résultats numériques au moyen de l'algorithme SIMPLER. On détermine les effets sur les performances des paramètres adimensionnels actifs tels que le nombre de Reynolds rotationnel, le nombre de Prandtl et la géométrie du système.

\section{NUMERISCHE UNTERSUCHUNG DES WÄRMEU゙BERGANGS BEI LAMINARER STRÖMUNG DURCH GLEICHSINNIG ROTIERENDE SCHEIBEN}

Zusammenfassung-Zur Beschreibung des Wärmeübergangs bei laminarer Strömung durch ein Paar gleichsinnig rotierender paralleler Kreisscheiben wurde ein theoretisches Modell entwickelt. Die Fluidströmung tritt von beiden Seiten in das Strömungsfeld ein und strömt radial nach außen. Das Verfahren der finiten Elemente wurde angewendet, um mit Hilfe des SIMPLER-Algorithmus numerische Ergebnisse zu bekommen. Der Einfluß der maßgeblichen dimensionslosen Größen wie Rotationszahl, Reynolds-Zahl, Prandtl-Zahl und der Geometrie auf den Wärmeübergang wird bestimmt. 
ЧИСЛЕННОЕ ИССЛЕДОВАНИЕ ТЕПЛОПЕРЕНОСА ПРИ ЛАМИНАРНОМ ТЕЧЕНИИ МЕЖДУ ПАРАЛЛЕЛЬНЫМИ ДИСКАМИ, ВРАЩАЮЩИМИСЯ

\section{В ПРОТИВОПОЛОЖНЫХ НАПРАВЛЕНИЯХ}

Аннотация-Разработана теоретическая модель для определения характеристик теплопереноса при ламинарном течении между двумя параллельными круглыми дисками, вращающимися в противоположных направлениях. Двуструйный поток поступает в поле течения с двух сторон и выходит наружу в радиальном направлении. Для голучения численных решений с нспользованием алгоритма SIMPLER применена конечно-разностная схема. Определено влияние на характеристики теплопереноса таких основных безразмерных параметров, как отнонение вращательного числа к критерию Рейнольдса, критерия Прандтля и геометрии системы. 